\title{
Chironomid (Diptera) distribution and diversity in Tibetan streams with different glacial influence
}

\author{
LADISLAV HAMERLÍK ${ }^{1,2}$ and DEAN JACOBSEN ${ }^{1}{ }^{1}$ Freshwater Biological Section, \\ Biology Department, University of Copenhagen, Hillerød, Denmark and ${ }^{2}$ Institute of Zoology, Slovak Academy of Sciences, \\ Bratislava, Slovakia
}

\begin{abstract}
We collected chironomid larvae and measured basic environmental variables in eight high mountain streams with different degrees of glacial influence in southern Tibet.

2. In total, 32 chironomid taxa were collected. The Orthocladiinae subfamily dominated both in taxon number and in abundance.

3. Both average taxon number and abundance were lower in glacier-fed streams compared with those of non-glacial origin. The total taxon number collected $(\gamma$ diversity) was similar regardless of glacial influence. However, spot diversity ( $\alpha$ diversity) was higher in non-glacial streams, while glacier-fed streams supported higher species turnover ( $\beta$ diversity).

4. Detrended correspondence analysis scattered the study sites along the first ordination axis, representing a combination of distance from glacier and channel stability. Two-way indicator analysis distinguished three groups of sites. Group 1 represented the sites closest to the glacier and were characterised by unstable channel conditions and low temperature with characteristic taxa Diamesa sp. 1, Orthocladius (Eud.) sp. and Rheocricotopus sp. Group 2 was made up of glacier-fed streams situated further from glaciers, with unstable channels and characterised by Orthocladius (Euo.) sp. Group 3 contained non-glacial streams as well as a glacier-fed stream further from the glacier margin. For these sites, stable channels and high conductivity were characteristic and Cricotopus (C.) sp., Pseudosmittia sp, Polypedilum sp., Eukiefferiella gracei group and Pagastia sp. 1 were the dominating taxa.

5. We propose a general distribution pattern of chironomids in the streams of glacial and non-glacial influence in Tibet, which is in accordance with the model proposed by Milner et al. (2001a) Freshwater Biology, 46, 1833-1847.
\end{abstract}

Key words. Aquatic insects, Chironomidae, diversity measures, glacier-fed streams, non-glacial streams, Tibetan Plateau, Himalayas.

\section{Introduction}

Glacier-fed streams provide distinctive, high-altitude habitats with characteristic biota (Ward, 1994). Even though glacial streams usually have low biological diversity, their communities are highly specialised and adapted to the cold water and fluctuating current. With the current climatic trends, awareness for glaciers and subsequently glacier-fed streams has gained attention

Correspondence: Ladislav Hamerlík, Institute of Zoology, Slovak Academy of Sciences, Dúbravská cesta 9, SK-84506 Bratislava, Slovakia. E-mail: ladislav.hamerlik@savba.sk worldwide. Patterns in biodiversity and community structure along the glacial gradient have been described from North America and Europe (Milner, 1994; Lods-Crozet et al., 2001b), New Zealand (Milner et al., 2001b), Greenland (Friberg et al., 2001) and high-altitude South America (Jacobsen et al., 2010). Although retreating glaciers may open new habitats and lengthen the stream gradient (Finn et al., 2010), glacial streams will eventually lose their in-flow. In addition, more sporadic precipitation will markedly change the temporal and spatial patterns of the stream flow. Changes in stream flow and temperature are expected to reduce species turnover ( $\beta$ diversity) and diversity at a regional scale ( $\gamma$ diversity) (Brown et al., 2007).

(C) 2011 The Authors

Insect Conservation and Diversity (C) 2011 The Royal Entomological Society 
Insects of the Chironomidae family are usually the dominant benthic dwellers of glacier-fed streams (Ward, 1994). The general distribution of biota in glacier-fed streams follows a similar pattern around the world: the communities closest to the glacier are rather poor (Milner et al., 2001a), yet composed of species adapted to that specific environment. The subfamily Diamesinae (especially Diamesa) dominates the reaches where $\mathrm{T}_{\max }<2{ }^{\circ} \mathrm{C}$, while the Orthocladiinae subfamily usually dominates where $\mathrm{T}_{\max }$ exceeds $2{ }^{\circ} \mathrm{C}$ (Milner et al., 2001a). With increasing distance from the glacier, temperature and channel stability increases, which is reflected in increased biological diversity and abundance (Lods-Crozet et al., 2001b; Milner et al., 2001a; Jacobsen et al., 2010). While chironomid communities of glacierfed streams of some zoogeographical regions, especially western Palaearctic, are well documented (e.g. Lods-Crozet et al., 2001b), other areas are almost unknown.

High-altitude streams of some regions of the Himalayas, such as Nepal, are relatively well studied (Roback \& Coffman, 1987; Rundle et al., 1993; Ormerod et al., 1994; Suren, 1994). And yet, the Tibetan part of the Himalayas, representing an ecologically interesting transition between the Palaearctic and Oriental region, has so far been overlooked. Streams in Tibet are some of the highest and least studied aquatic ecosystems in the world. They cover a wide area, contributing large quantities of glacial melt water, and many of them are still relatively pristine. Although the current atmospheric warming and glacial retreat in Tibet has probably affected the streams (Yao et al., 2007), the effects are likely to intensify in the future. The possible consequences on ecological processes and aquatic biodiversity in Tibetan streams have yet to be evaluated. For example, we do not know which species, if any, might be lost when glaciers are reduced even further or have disappeared altogether.

During a Sino-Danish multidisciplinary Tibetan expedition, we took the opportunity to survey the aquatic macroinvertebrate fauna in streams on the Tibetan Plateau. The overall objective of this paper is (1) to describe the chironomid distribution pattern of the streams of the Tibetan Plateau, particularly in relation to glacial influence on stream flow and (2) to estimate the effect of glacial influence on the biodiversity in different scales $(\alpha, \beta$ and $\gamma)$. Our hypothesis is that glacier-fed streams support taxa characteristic to that particular stream type, and therefore increase regional biodiversity of Tibetan streams.

\section{Material and methods}

\section{Study area}

Eight small streams (1-8 $\mathrm{m}$ in width) located at altitudes between 4990 and $4315 \mathrm{~m}$ in three areas of southern Tibet were surveyed during July 2009: the Karola glacier (sites 1 and 2), JiaCun (sites 3-6) and Nyanchentangla (sites 7 and 8) (Fig. 1). Five of the streams were glacier fed, but located at varying distances from the glaciers, and site 1 represented an outlet stream of a lake with glacial influence. The remaining three streams had no glacial influence. Spot measurements of water temperature, conductivity, $\mathrm{pH}$, oxygen saturation, and water turbidity were taken in the field with portable meters. Current velocity, periphyton biomass, and channel stability were visually estimated on the site and assigned to three categories. Current: moderate (approximately $0.1-0.3 \mathrm{~ms}^{-1}$ ), fast (approximately $0.3-0.6 \mathrm{~ms}^{-1}$ ) or strong (approximately $0.6-1.0 \mathrm{~ms}^{-1}$ ). Periphyton: none (no detached biofilm upon scraping of stones), moderate (stones with some algal dominated biofilm), or high (stones completely smothered in algal growth). Channel stability: unstable (wandering channel with lower banks consisting of loose pebble \& cobble), fairly stable (part of the banks vegetated and other parts eroding), or stable (completely vegetated lower banks). Distance to feeding glaciers was measured using Google Earth. For stream characteristics see Table 1 .

\section{Benthos sampling}

At each site, five quantitative Surber samples $\left(500 \mathrm{~cm}^{2}\right.$, mesh size of $200 \mu \mathrm{m}$ ) were collected randomly from pebble-cobble substratum in riffle/run habitats. The material collected was placed into plastic bottles, labelled and preserved with 75\% ethanol. In the laboratory, chironomid larvae were sorted, counted and mounted in Berlese fluid under a low-power stereomicroscope. Identification of larvae was made under high magnification $(400 \times)$ to the lowest possible level following Wiederholm (1983), Roback and Coffman (1987), and Makarchenko and Makarchenko (2000).

\section{Statistical methods}

Glacial influence of the glacier-fed streams, used for calculating correlations with number of taxa and abundance, was expressed tentatively as a reciprocal value of the log-transformed distance from the feeding glacier, where non-glacial streams had a 0 value of glacial influence. To test the significance of differences in taxa number and density of glacier-fed and non-glacial streams, $t$-test was performed. Site 1 , representing an outlet stream, was excluded from this analysis. Spot diversity $(\alpha$ diversity) was defined as the mean number of taxa found at one locality. The regional taxon richness ( $\gamma$ diversity) was estimated as the total number of taxa in a collection of samples found in glacier-fed and non-glacial streams, respectively. Two measures of species turnover ( $\beta$ diversity) were used. Cody's $\beta$ :

$$
\beta_{\mathrm{c}}=\frac{\mathrm{g}(\mathrm{H})+\mathrm{l}(\mathrm{H})}{2}
$$

where $\mathrm{g}(\mathrm{H})$ is the number of species gained and $1(\mathrm{H})$ the number lost moving along the transect (Wilson \& Shmida, 1984) was calculated using the software package Species Richness and Distribution (Seaby \& Henderson, 2004). The second measure was the proportion of the within-site diversity occurring in the regional species pool $(\gamma / \alpha)$. To test the significance of the observed level of the $\beta$ diversity, diversity partition was conducted using PARTITION 3.0 (Veech \& Crist, 2009). Individual-based randomization combined with balanced sampling design was used to calculate the expected values. Randomization level was set on 1000. The power of the individual-based randomization method was estimated by comparing the sampling distribution of the diversity 

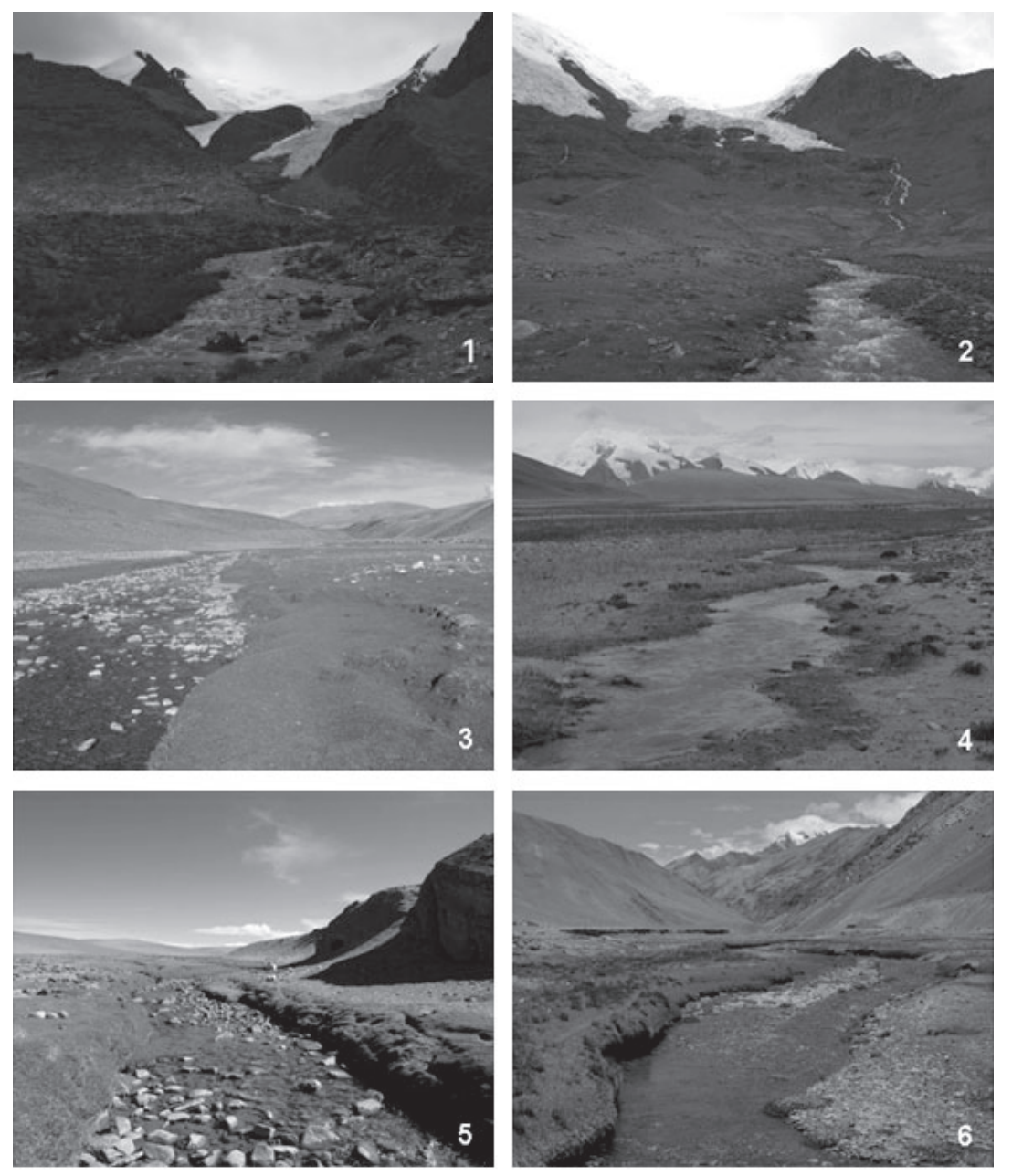

Fig. 1. View of the sampling sites. Sites 1, 2, 4, 7 and 8 represent glacier-fed streams; sites 3, 5 and 6 have no glacial influence (Photo D. Jacobsen).
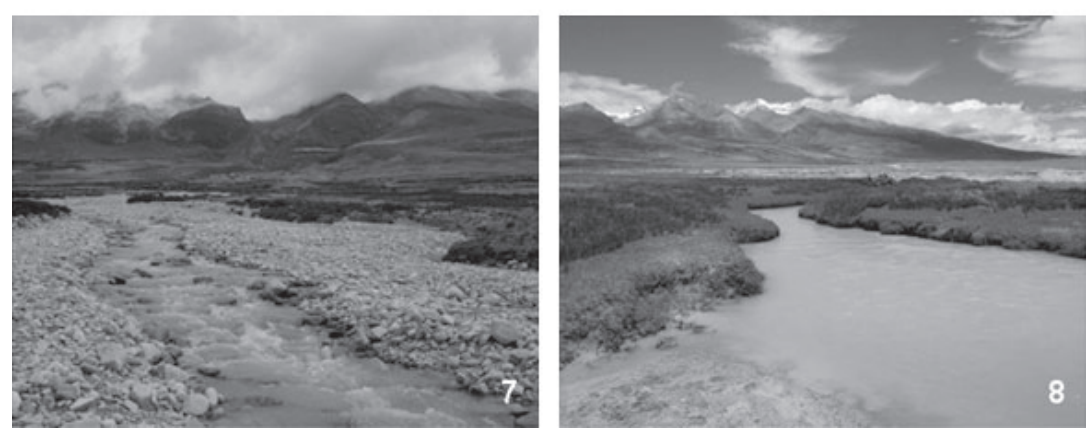

component with its corresponding null distribution (J. A. Veech and T. O. Crist, unpubl. data).

Detrended correspondence analysis (DCA) was used to visualise the distribution of species data along a main environmental gradient using CANOCO 4.5 package (ter Braak \& Šmilauer, 2002). Species abundance data (ind. $\mathrm{m}^{-2}$ ) were $\log _{10}(x+1)$ transformed prior to the analyses. Different stream types were distinguished based on two-way indicator species analysis (TWINSPAN; Hill, 1979). The result was displayed in a DCA sample plot as groups distinguished by different symbols. Analysis of similarity
(ANOSIM, Clarke \& Green, 1988) was performed to test the significance of the groups that had been defined according to TwINSPAN. Similarity percentage analysis (SIMPER, Community Analysis Package Version 3.0, Pisces Conservation Ltd., Lymington, UK) was used to determine the contribution of each species to the observed similarity within each group. It allowed us to identify the species that are most important in creating the observed pattern of similarity. Both SIMPER and ANOSIM was performed using the Community Analysis Package 3.0 (Seaby \& Henderson, 2004).

(c) 2011 The Authors

Insect Conservation and Diversity (c) 2011 The Royal Entomological Society, Insect Conservation and Diversity, 5, 319-326 


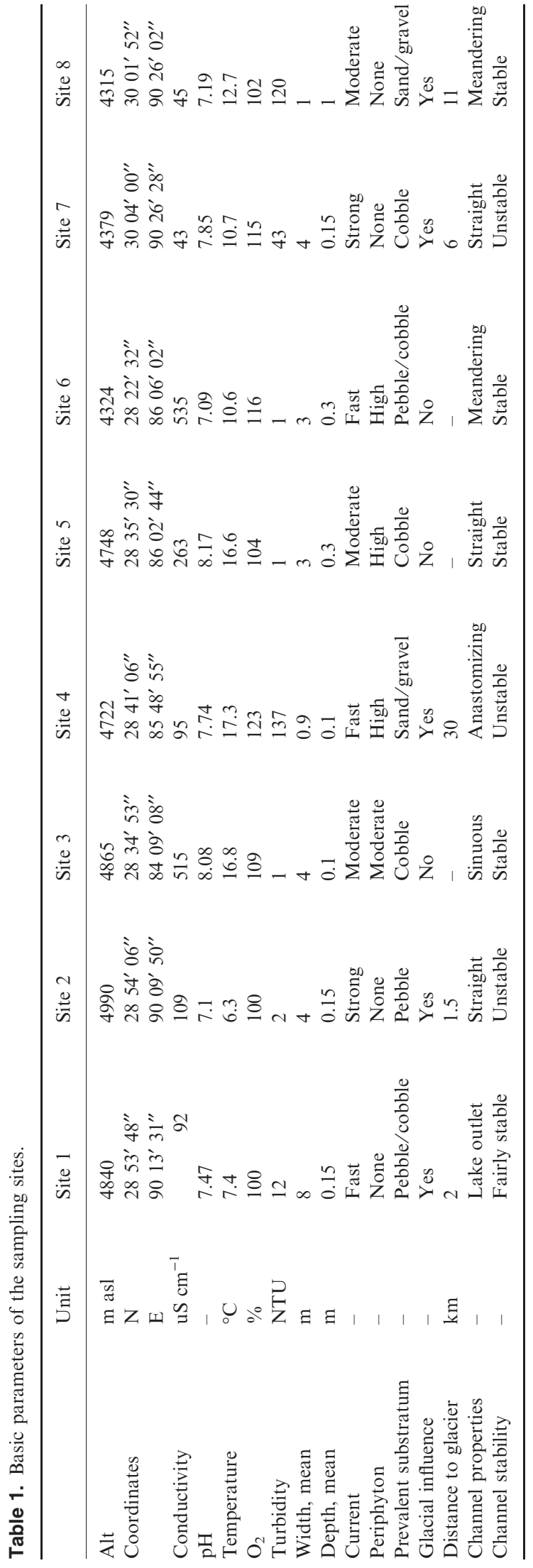

\section{Results}

Water temperature of the eight study sites varied from 6.3 to $17.3{ }^{\circ} \mathrm{C}$ and increased with distance from the feeding glacier in glacier-fed streams. Turbidity varied from 2 to 137 NTU in the glacial sites, but was very low ( $<1 \mathrm{NTU})$ in all non-glacial sites. Conductivity was lower in glacial sites $\left(43-109 \mu \mathrm{S} \mathrm{cm}^{-1}\right)$ than in non-glacial sites $\left(263-535 \mu \mathrm{S} \mathrm{cm}^{-1}\right)$. $\mathrm{pH}$ did not show a correlation with the distance from the glacier or glacial origin and varied from 7.1 to 8.2. For more environmental parameters of the streams see Table 1.

We collected 32 taxa from three chironomid subfamilies (Appendix S1). The subfamily Orthocladiinae dominated both in number of taxa (20) and abundance (approximately 90\% of all specimens). Diamesinae and Chironominae, with six taxa each, represented approximately $6 \%$ and $4 \%$ of the total abundance, respectively. Within the Chironominae, the Tanytarsini predominated with five taxa. Taxon number varied from 4 to 11
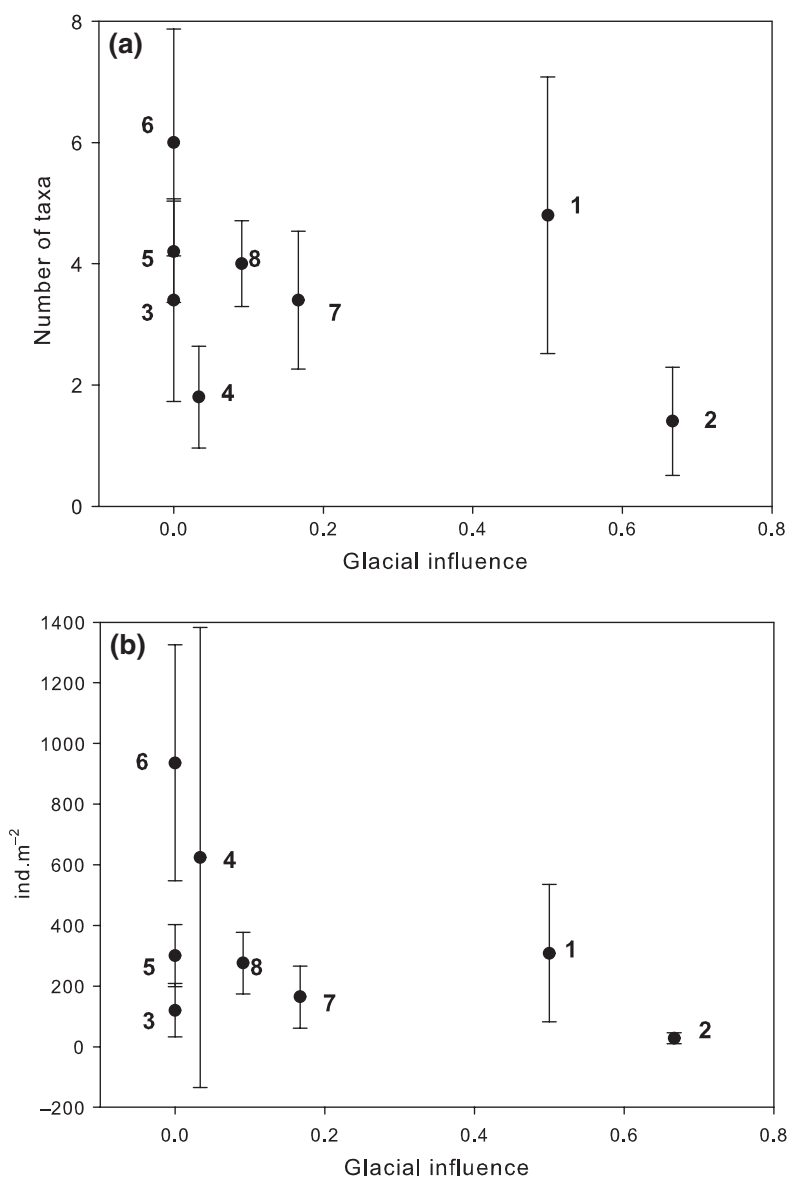

Fig. 2. Scatter plots of average number of taxa (a) and density (b) recorded in each site ordered along increasing glacial influence. Plots represent mean values, error bars represent standard deviations (SD). Numbers 1-8 refer to the sites. Glacial influence of the glacier-fed streams was expressed tentatively as a reciprocal value of the log-transformed distance from the feeding glacier; non-glacial streams had 0 value. 
Table 2. Data on $\alpha, \beta$ and $\gamma$ diversity of chironomids from streams of glacial and non-glacial origin. Two measures of $\beta$-diversity are presented: Cody's $\beta$ and the proportion of the within-site diversity occurring in the regional species pool $(\gamma / \alpha)$. In glacial streams, the diversity measures were calculated both including (Incl. S1) and excluding (Excl. S1) the lake outlet stream site.

\begin{tabular}{lccccc}
\hline & & \multicolumn{3}{c}{$\beta$} & \\
\cline { 4 - 5 } Diversity & & $\alpha$ & Cody's $\beta$ & $\gamma / \alpha$ & $\gamma$ \\
\hline Glacial streams & Incl. S1 & 7 & 15.5 & 3.57 & 25 \\
\multirow{2}{*}{ Non-glacial streams } & Excl. S1 & 6 & 13.5 & 3.33 & 20 \\
& & 10 & 7.0 & 1.80 & 19 \\
\hline
\end{tabular}
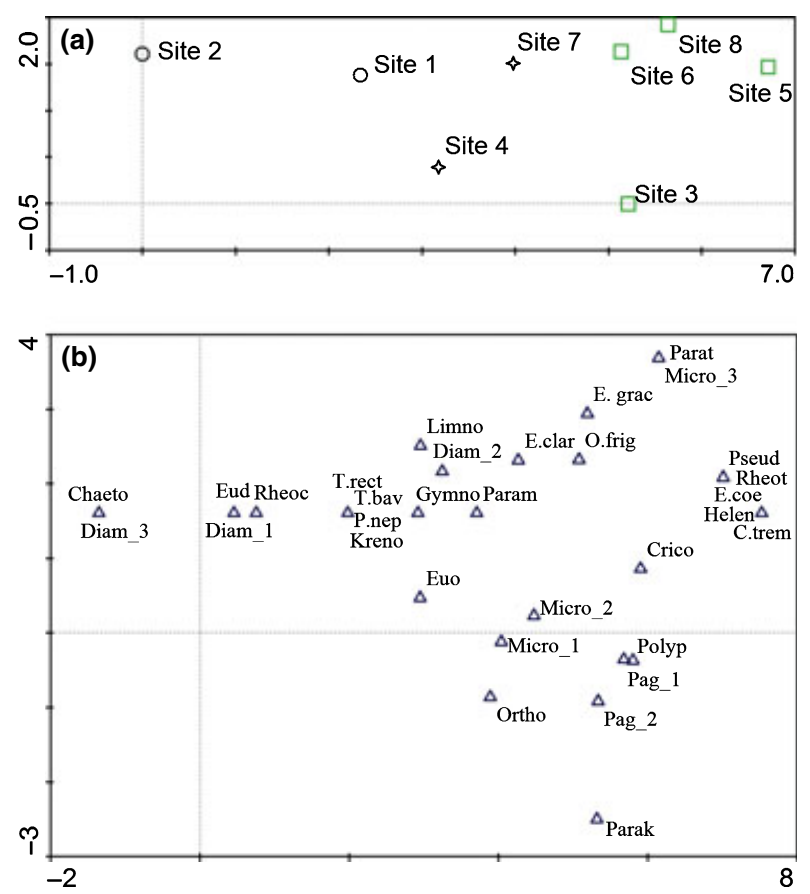

Fig. 3. Detrended correspondence analysis of sites (a) and chironomid taxa (b). Symbols represent different stream types, distinguished with TWINSPAN: circles $=$ Group $1-$ glacier-fed streams close to the glacier; stars $=$ Group $2-$ glacier-fed streams far from the glacier; squares $=$ Group 3 - non-glacial and glacierfed streams with stable channel.

per site with 14 taxa collected from glacier-fed streams and seven taxa only from non-glacial streams (Fig. 2a). The average density was low, varying from 28 to 936 ind. $\mathrm{m}^{-2}$ (Fig. 2b). Both average taxon number and density was lower in glacier-fed streams compared with those of the non-glacial origin, but only the difference in taxa number was significant $(P<0.033)$. Neither taxon number nor abundance was correlated significantly with the degree of glacial influence.

Excluding the lake outlet (site 1), total richness ( $\gamma$ diversity) for the glacier-fed streams was 20 taxa and 19 taxa for non-gla-

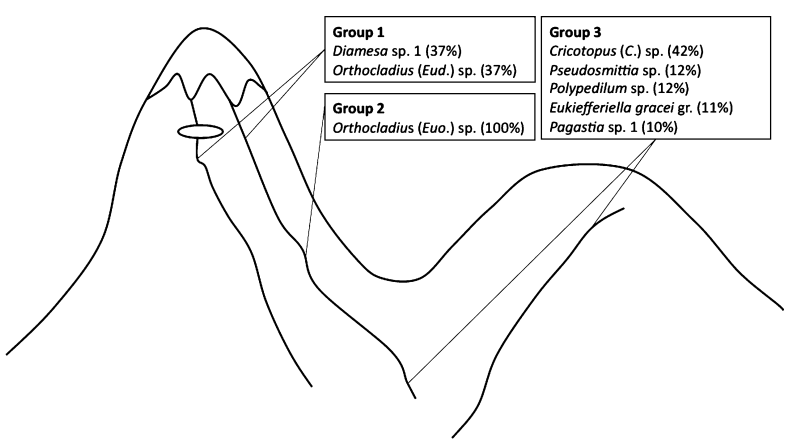

Fig. 4. Scheme of an idealised distribution pattern of the characteristic chironomid taxa. Numbers in parentheses after each taxa represent the share on the within-group similarity calculated by Similarity percentage analysis (SIMPER); taxa with $<10 \%$ distribution are not pictured.

cial streams. Average within-site $(\alpha)$ diversity was higher in nonglacial streams (10 taxa) than in glacial streams (six taxa). On the contrary, taxon turnover (Cody's $\beta$ ) was higher in the glacial streams (13.5) compared with streams without glacial influence (7.0). The observed proportion of within-site diversity occurring in the regional species pool $(\gamma / \alpha)$ represented 3.3 and 1.8 $(P<0.001)$ in glacier-fed and non-glacial streams, respectively. For overview of diversity measures, see Table 2.

The first two ordination axes of the DCA explained 33.7\% variability of the taxon data (gradient lengths 6.7 SD, Fig. 3a,b). Generally, from left to right, both distance from glacier and channel stability increased. TWINSPAN distinguished three groups of sites with similar communities and conditions. Group 1 (streams 2 and 1) is situated in the left part of the ordination diagram, representing the closest sites to the glacier having unstable channel conditions and low temperature (7.4 and $6.3{ }^{\circ} \mathrm{C}$, respectively) as well as the highest altitude among all sites. The characteristic species for this group were Diamesa sp. 1, Orthocladius (Eud.) sp. and Rheocricotopus sp. (SIMPER, Fig. 4). Group 2 consists of glacier-fed streams being situated further from the glacier and showing unstable channel conditions (sites 4 and 7). The single taxon characteristic of this group was Orthocladius (Euo.) sp. Group 3 contained all the non-glacial streams (sites 3, 5 and 6) as well as a glacier-fed stream (site 8) located $11 \mathrm{~km}$ from the glacier margin. The common features of the group 3 streams were stable channel conditions and high conductivity (only in the non-glacial streams). For these streams, Cricotopus (C.) sp., Pseudosmittia sp., Polypedilum sp., Eukiefferiella gracei group and Pagastia sp. 1 were the most characteristic. According to ANOsIM, the chironomid assemblages of the three groups were not significantly different (however, both group 1 and 2 differed from group 3 on level $P=0.06$ ).

\section{Discussion}

We expected that the Tibetan streams would follow the typical pattern of low community diversity closest to the glacier, while downstream, the biological community will increase in abun- 
dance and species diversity. Indeed, there was an overall tendency of decreasing diversity and abundance of the chironomids with increasing glacial influence. Orthocladiinae dominated in all sites, most likely because metakryal habitats $\left(\mathrm{T}_{\max }<2{ }^{\circ} \mathrm{C}\right.$, sensu Steffan, 1971) were not included. However, as expected, with higher glacial influence, the proportion of Diamesinae (mostly Diamesa) increased. On the contrary, with decreasing glacial influence, Chironominae became more abundant at the expense of Orthocladiinae. A high proportion of Diamesa at relatively high water temperatures $(>40 \%$ of total abundance at $6.3{ }^{\circ} \mathrm{C}$ in site 2) supports the findings of Lods-Crozet et al. (2001a) that populations of Diamesa can be maintained in warmer temperatures in unstable channels, where other chironomids are not abundant. However, in case of the glacial sites being located further from the glacier with unstable channels (sites 4 and 7), Diamesa (and other Diamesinae) were either not present or represented a negligible part of the community assembly. The most likely reason for its absence was the high water temperature, 10.7 and $17.3{ }^{\circ} \mathrm{C}$. The optimal temperature calculated for European Diamesa was 6-7 ${ }^{\circ} \mathrm{C}$ (Castella et al., 2001), but in European glacier-fed streams, some species of the genus could maintain abundant populations even in warmer environments $\left(\mathrm{T}_{\max } \leq 15^{\circ} \mathrm{C}\right.$, Lods-Crozet et al., 2001b).

Characterisation of the sites closest to the glacier (group 1) by Orthocladius (Eud.) sp. and Orthocladius (Euo.) sp. in the sites further down from the glacier with unstable channels (group 2, Fig. 4) was in accordance with the model of Milner et al. (2001a). The subgenus Eudactylocladius often dominates the fauna of thin water films in temperate regions. We assume that it is not the low temperature alone, but rather the combination of unstable channel and low temperature, typical for streams with high glacial influence, which provides optimal conditions for this taxon. Species of the Euorthocladius subgenus represents the dominant Orthocladiinae in glacier-fed streams, such as Orthocladius (Euo.) frigidus (which has recently been moved to the Mesorthocladius subgenus (Saether, 2005) and O. (Euo.) rivicola group in Europe (Milner et al., 2001a) or O. (Euo.) thienemanni Kieffer in western Greenland (Friberg et al., 2001). Generally, species of the genus Orthocladius, along with Tvetenia and Eukiefferiella, are able to colonise the reaches very close to the glacier terminus at mean temperature close to $0{ }^{\circ} \mathrm{C}$ (Milner, 1994; Lods-Crozet et al., 2001b; Lencioni \& Rossaro, 2005) and in unstable channels. We recorded Tvetenia bavarica group only in a glacial site and Eukiefferiella claripennis and E. gracei groups occurred in both non-glacial and glacier-fed streams.

Group 3 contained all the non-glacial sites and the only glacial site with stable channel conditions. The characteristic taxa for these sites were Cricotopus (C.) sp., Pseudosmittia sp., Polypedilum sp., Eukiefferiella gracei group and Pagastia sp. 1. With the exception of Pagastia, all the taxa have been found in glacial streams in the Alps, Norway, Iceland or Svalbard (Lods-Crozet et al., 2001b), but always far from the glacier or after a confluence with a non-glacial tributary (Maiolini \& Lencioni, 2001). Even though the Eukiefferiella gracei group has not been collected in the studies mentioned, a number of Eukiefferiella species were well represented in subkryal, glacio-rhitral and kreno-rhitral Alpine streams (Lods-Crozet et al., 2001b; Lencioni \& Rossaro, 2005). The genus Pagastia was frequent in the Tibetan non-glacial streams, but absent in the European streams, which is given by the Nearctic and eastern Palaearctic geographical distribution of the genus (Makarchenko \& Makarchenko, 2000).

There was a significant difference in the taxon richness between the two glacier-fed streams situated closest to the glacier: site 1 , representing a lake outlet, supported two-fold more taxa than site 2 . This finding supports the role of lakes as modifiers of the conceptual model of species distribution by improving the physical conditions further downstream, allowing increased faunal diversity suggested by Milner and Petts (1994) and supported by others (e.g. Burgherr \& Ward, 2000; Brittain et al., 2001).

In contrary to our hypothesis, the total taxa number collected ( $\gamma$ diversity) in the Tibetan streams with and without glacial influence was similar. However, $\alpha$ diversity was higher in non-glacial streams, while glacier-fed streams supported higher $\beta$ diversity (species turnover). This result supports the finding of Brown et al. (2007), who suggested that with future meltwater reductions, $\alpha$ diversity of streams fed by meltwater will increase, while $\beta$ diversity will be reduced. The main reason for this is the decrease in habitat heterogeneity associated with spatiotemporal variability of water source, as contributions will become lower.

With reduced meltwater contributions, extinction of some oligo-stenothermal and endemic alpine aquatic species is expected (Rossaro et al., 2006; Brown et al., 2007), which leads to decreases in $\gamma$ diversity. However, Finn et al. (2010) found no evidence for local extinction even in streams fed from a dramatically receding glacier. They observed a general upward movement of a biota: taxa specialised on pro-glacial conditions have colonised the upper extent of the newly formed section, while common species typical for lower altitude streams have colonised the lower section of the gradient. Complete loss of glaciers will, however, have a much stronger impact on the aquatic assemblages, imposing a real threat of extinction of the pro-glacial species.

To find the species most threatened by glacial retreat in Tibet, we focused on the sites located closest to the glacier margin. There were only two taxa collected in site 2 not occurring in other sites: Diamesa sp. 3 and Chaetocladius sp. The other taxa (Diamesa sp. 1, Rheocricotopus sp. and Orthocladius (Eud.) sp.) occurred also in site 1 , representing a lake outlet with a more benign environment, and these are therefore not likely to be threatened by glacier retreat. Roback and Coffman (1987) collected larvae of the Chaetocladius genus both in streams with glacial and non-glacial origin distributed between altitudes 2480 $3500 \mathrm{~m}$, and it was not characteristic to glacier-fed streams only. Moreover, the Chaetocladius genus is frequent not only in kryal, but also in rhitral and krenal streams (Lencioni \& Rossaro, 2005). To discover whether some species of the Chaetocladius genus could be restricted to glacier-fed streams, higher taxonomic resolution would be necessary. Based on the distribution of Diamesa sp. 3 in the streams studied, the ecological requirements and meltwater distribution optima of the genus (Brown et al., 2007), this species seems to be the most threatened by glacier retreat. Unfortunately, because only larvae were captured, it was not possible to identify the species of the genera. To deter- 
mine which species may go extinct with a complete disappearance of glaciers, more comprehensive knowledge of the community structure and distribution of the fauna at species-level in glacier-fed as well as in non-glacial streams is essential.

\section{Acknowledgement}

We thank Heather Mariash for proofreading and helpful notes. We also acknowledge the helpful comments provided by the anonymous reviewers. We are very grateful to the Danish Ministry of Science, Technology and Innovation who funded the field expedition and to the Innovation Centre Denmark at the Royal Danish Consulate in Shanghai for logistic planning.

\section{Supporting Information}

Additional Supporting Information may be found in the online version of this article under the DOI reference: doi: 10.1111/ j.1752-4598.2011.00167.x:

Appendix S1. Average density (ind. $\mathrm{m}^{-2}$ ) of the chironomid taxa recorded.

Please note: Neither the Editors nor Wiley-Blackwell are responsible for the content or functionality of any supporting materials supplied by the authors. Any queries (other than missing material) should be directed to the corresponding author for the article.

\section{References}

ter Braak, C.J.F. \& Šmilauer, P. (2002) CANOCO Reference Manual and Users Guide to Canoco for Windows. Software for Canonical Community Ordination (version 4), Centre of Biometry, Wageningen.

Brittain, J.E., Saltveit, S.J., Castella, E., Bogen, J., Bønsnes, T.E., Blakar, I., Bremnes, T., Haug, I. \& Velle, G. (2001) The macroinvertebrate communities of two contrasting Norwegian glacial rivers in relation to environmental variables. Freshwater Biology, 46, 1723-1736.

Brown, L.E., Hannah, D.M. \& Milner, A.M. (2007) Vulnerability of alpine stream biodiversity to shrinking glacier and snowpacks. Global Change Biology, 13, 958-966.

Burgherr, P. \& Ward, J.V. (2000) Zoobenthos of kryal and lake outlet biotopes in a glacial flood plain. Verhandlungen der Internationalen Vereinigung für Theoretische und Angewandte Limnologie, 27, 1587-1590.

Castella, E., Adalsteinsson, H., Brittain, J.E., Gislason, G.M., Lehmann, A., Lencioni, V., Lods-Crozet, B., Maiolini, B., Milner, A.M., Olafsson, J.S., Saltveit, S.J. \& Snook, D.L. (2001) Macrobenthic invertebrate richness and composition along a latitudinal gradient of European glacier-fed streams. Freshwater Biology, 46, 1811-1831.

Clarke, K.R. \& Green, R.H. (1988) Statistical design and analysis for a biological effect study. Marine Ecology Progress Series, 46, 213-226.

Finn, D.S., Räsänen, K. \& Robinson, C.T. (2010) Physical and biological changes to a lengthening stream gradient following a decade of rapid glacial recession. Global Change Biology, 16, 3314-3326.

Friberg, N., Milner, A.M., Svendsen, L.M., Lindegaard, C. \& Larsen, S.E. (2001) Macroinvertebrate stream communities along regional and physico-chemical gradients in Western Greenland. Freshwater Biology, 46, 1753-1764.

Hill, M.O. (1979) TWINSPAN - A Fortran Program for Arranging Multivariate Data in an Ordered Two-Way Table by Classification of the Individuals and Attributes. Selection of Ecology and Systematics, Cornell University, Ithaca, New York.

Jacobsen, D., Dangles, O., Andino, P., Espinosa, R., Hamerlík, L. \& Cadier, E. (2010) Longitudinal zonation of macroinvertebrates in an Ecuadorian glacier-fed stream: do tropical glacial systems fit the model? Freshwater Biology, 55, 1234 1248.

Lencioni, V. \& Rossaro, B. (2005) Microdistribution of chironomids (Diptera: Chironomidae) in alpine streams: an autecological perspective. Hydrobiologia, 53, 61-76.

Lods-Crozet, B., Castella, E., Cambin, D., Ilg, C., Knispel, S. \& Mayor-Siméant, H. (2001a) Macroinvertebrate community structure in relation to environmental variables in Swiss glacial stream. Freshwater Biology, 46, 1641-1661.

Lods-Crozet, B., Lencioni, V., Ólafsson, J.S., Snook, D.L., Velle, G., Brittain, J.E., Castella, E. \& Rossaro, B. (2001b) Chironomid (Diptera: Chironomidae) communities in six European glacier-fed streams. Freshwater Biology, 46, 1791-1809.

Maiolini, B. \& Lencioni, V. (2001) Longitudinal distribution of macroinvertebrate assemblages in a glacially influenced stream system in the Italian Alps. Freshwater Biology, 46, $1625-1639$.

Makarchenko, E.A. \& Makarchenko, M.A. (2000) Revision of Pagastia Oliver, 1959 (Diptera, Chironomidae) of the Holarctic region. Late 20th Century Research on Chironomidae: An Anthology from the 13th International Symposium on Chironomidae (ed. by O. Hoffrichter), pp. 171-176. Shaker Verlag, Aachen, Germany.

Milner, A.M. (1994) Colonisation and succession of invertebrate communities in a new stream in Glacier Bay National Part, Alaska. Freshwater Biology, 32, 387-400.

Milner, A.M., Brittain, J.E., Castella, E. \& Petts, G.E. (2001a) Trends of macroinvertebrate community structure in glacier-fed rivers in relation to environmental conditions: a synthesis. Freshwater Biology, 46, 1833-1847.

Milner, A.M. \& Petts, G.E. (1994) Glacier rivers: physical habitat and ecology. Freshwater Biology, 32, 195-307.

Milner, A.M., Taylor, R.C. \& Winterbourn, M.J. (2001b) Longitudinal distribution of macroinvertebrates in two glacier-fed New Zealand rivers. Freshwater Biology, 46, 1765-1775.

Ormerod, S.J., Rundle, S.D., Wilkinson, S.M., Daly, G.P., Dale, K.M. \& Juttner, I. (1994) Altitudinal trends in the diatoms, bryophytes, macroinvertebrates and fish of Nepalese river system. Freshwater Biology, 32, 309-322.

Roback, S.S. \& Coffman, W.P. (1987) Results of the Nepal Alpine Zone Research Project, Chironomidae (Diptera). Proceedings of the Academy of Natural Sciences of Philadelphia, 139, 87-158.

Rossaro, B., Lencioni, V., Boggero, A. \& Marziali, L. (2006) Chironomids from southern Alpine running waters: ecology, biogeography. Hydrobiologia, 562, 231-246.

Rundle, S.D., Jenkins, A. \& Ormerod, S.J. (1993) Macroinvertebrate communities in streams in the Himalaya, Nepal. Freshwater Biology, 30, 169-180. 
Saether, O.A. (2005) A new subgenus and new species of Orthocladius van der Wulp, with a phylogenetic evaluation of the validity of the subgenera of the genus (Diptera: Chironomidae). Zootaxa, 974, 1-56.

Seaby, R.M.H. \& Henderson, P.A. (2004) Community Analysis Package 3.0. Pisces Conservation Ltd, Lymington.

Steffan, A.W. (1971) Chironomid (Diptera) biocoenoses in Scandinavian glacier brooks. The Canadian Entomologist, 103, 477486.

Suren, A.M. (1994) Macroinvertebrate communities of streams in western Nepal: effects of altitude and land use. Freshwater Biology, 32, 323-326.

Veech, J.A. \& Crist, T.O. (2009) PARTITION: software for hierarchical partitioning of species diversity, version 3.0. < http:// www.users.muohio.edu/cristto/partition.htm > 6th June 2011.

Ward, J.V. (1994) Ecology of alpine streams. Freshwater Biology, 32, 277-294.
Wiederholm, T. (ed.) (1983) Chironomidae of the Holarctic region keys and diagnoses. Part I Larvae. Entomologica Scandinavica, Supplement, 19, 1-457.

Wilson, M.V. \& Shmida, A. (1984) Measuring beta diversity with presence-absence data. Journal of Ecology, 72, 1055-1064.

Yao, T., Pu, J., Lu, A., Wang, Y. \& Yu, W. (2007) Recent glacial retreat and its impact on hydrological processes on the Tibetan Plateau, China, and surrounding regions. Arctic, Antarctic, and Alpine Research, 39, 642-650.

Accepted 15 July 2011

First published online 19 September 2011

Editor: Yoshitaka Tsubaki

Associate editor: Thomas Crist 